\title{
Effect of $\mathbf{N}^{\mathrm{G}}$-Monomethyl-L-Arginine on Regional Vascular Resistance in Rats
}

\author{
Tetsuya Nakamura, M.D., Tetsuo Sakamaki, M.D., \\ Kunio Sato, M.D., Zenpei Ono, M.D., \\ and Russell L. PrewitT, Ph.D.*
}

\begin{abstract}
SuMmary
This study investigated the effects of intravenous injection of the specific inhibitor of nitric oxide (NO) formation, $\mathrm{N}^{\mathrm{G}}$-monomethyl-L-arginine (LNMMA), on mean arterial pressure and regional vascular resistance in rats $(n=7)$. Regional vascular resistances of brain, heart, left kidney, intestine (jejunum), left testis and right testis were measured using radiolabelled microspheres before and after injection of $12.5 \mathrm{mg} / \mathrm{kg}$ of L-NMMA. Injection of L-NMMA raised mean arterial pressure significantly $(p<0.05)$ from $119 \pm 4$ (mean \pm $\mathrm{SEM}) \mathrm{mmHg}$ to $139 \pm 7 \mathrm{mmHg}$, accompanied by a significant $(p<0.05)$ decrease in both heart rate and cardiac index and an increase in total peripheral resistance. Regional vascular resistances in brain, heart, kidney and intestine increased significantly $(p<0.05)$ with L-NMMA, but no change was observed in the testes. The results indicate that the resistance of vascular beds is affected by NO synthesis, while the extent of regulation may differ among the various vascular beds. (Jpn Heart J 35: 363-368, 1994)
\end{abstract}

Key words: Nitric oxide Endothelium-derived relaxing factor Microspheres Regional blood flow

$\mathrm{V}$

ASCULAR endothelial cells release endothelium-derived relaxing factor (EDRF), which produces the vascular smooth muscle relaxant response to acetylcholine (ACh). EDRF has been characterized pharmacologically and identified chemically as nitric oxide (NO). ${ }^{2}$ The formation of $\mathrm{NO}$ from L-arginine by endothelial cells in culture has been demonstrated, ${ }^{3,4)}$ and this biosynthetic process is inhibited by the $\mathrm{L}$-arginine analogue $\mathrm{NG}^{\mathrm{G}}$-monomethyl-L-arginine ( $\mathrm{L}$ NMMA) ${ }^{5,6)}$ L-NMMA ${ }^{7)}$ causes a dose-dependent increase in mean arterial pressure in anesthetized rabbits and reduces release of NO from isolated rabbit aorta in vitro. Furthermore, the elevation of arterial pressure and the reduction in ex vivo

From the Second Department of Internal Medicine, Gunma University School of Medicine, Maebashi Japan, and *Department of Physiology, Eastern Virginia Medical School, Norfolk, Virginia USA.

Address for correspondence: Tetsuya Nakamura, M.D., The Second Department of Internal Medicine, Gunma University School of Medicine, Maebashi 371, Japan.

Received for publication August 9, 1993.

Accepted March 7, 1994. 
release of $\mathrm{NO}$ are both reversed by L-arginine. ${ }^{7)}$ These observations indicate that in vivo, the formation of NO by vascular endothelial cells plays an important role in the control of blood pressure.

A rise in blood pressure with the intravenous injection of L-NMMA is characterized by increased peripheral vascular resistance. However, it is not well established which vascular beds contribute to this elevation in total peripheral resistance or to what extent the resistances are increased in individual organs. ${ }^{8,9}$ In the present study, we have investigated the role of NO in the maintenance of blood pressure by examining the regional hemodynamic consequences of inhibiting endothelial NO production with L-NMMA. We studied uninephrectomized rats because uninephrectomy is performed frequently to induce animal models of hypertension and is meaningful to clarify the hemodynamic status of these animals.

\section{Methods}

Animals: Male Wistar rats (Charles River Laboratory, Wilmington, MA, USA) were anesthetized with ketamine hydrochloride $(60 \mathrm{mg} / \mathrm{kg}$ i.p.) and xylazine $(10$ $\mathrm{mg} / \mathrm{kg}$ i.p.) at the age of 6-7 weeks. Body weight was $218 \pm 8 \mathrm{~g}(n=7$, mean \pm SEM). After an abdominal incision, the right kidney was removed. Penicillin $G$ (25,000 units i.m.) was injected after the surgery. The rats were caged individually, fed Purina rat chow and water ad libitum, and maintained on a 12-hour light/dark cycle until their use in experiments 4 weeks later.

Experimental protocol: Rats were anesthetized with sodium thiopental, (100 $\mathrm{mg} / \mathrm{kg}$ i.p.). The trachea was intubated (PE-240), and the right carotid artery, left femoral artery and left femoral vein were cannulated (PE-90). The left femoral arterial cannula was connected to a transducer (Statham), and systemic arterial pressure was monitored continuously on a recorder. The right carotid arterial cannula was advanced into the left ventricle. This cannula was also connected to a transducer and the pressure was recorded. The position of the carotid arterial cannula was verified by the characteristic left ventricular pressure tracing and by inspection at necropsy.

Cardiac output and regional vascular resistances were measured by the reference sample technique, using microspheres labeled with ${ }^{14} \mathrm{Ce}$ or ${ }^{85} \mathrm{Sr}(3 \mathrm{M}$ Company, St. Paul, Minnesota) averaging $13.4 \pm 0.5 \mu \mathrm{m}$ and $13.8 \pm 0.7 \mu \mathrm{m}$ in diameter, respectively. The measurements were made in each animal before and after the administration of L-NMMA, and the order of the injection of microspheres labeled with ${ }^{141} \mathrm{Ce}$ or ${ }^{85} \mathrm{Sr}$ was randomized. The microspheres were suspended in saline with one drop of $0.05 \%$ Tween 80 . To prevent sphere aggregation, the suspension was dispersed in an ultrasonic bath, and then shaken on a 
vortex mixer immediately before injection. Approximately 468,000 spheres $(0.2$ $\mathrm{ml}$ ) were injected into the left ventricle via the right carotid arterial cannula. A reference sample of blood was withdrawn at a known rate $(0.65 \mathrm{~m} l / \mathrm{min})$ from the femoral artery $15 \mathrm{sec}$ before microsphere injection, during the microsphere injection and for a total of $120 \mathrm{sec}$ thereafter, thereby creating a "reference" organ. After the microsphere injection, the carotid arterial cannula was attached to a syringe and flushed with $0.2 \mathrm{ml}$ of saline. Microsphere injection had no discernible effect on either heart rate or ventricular systolic pressure.

After completion of the reference sample withdrawal, the withdrawn blood volume $(1.46 \mathrm{ml})$ was replaced with a transfusion of heparinized blood of donor rats. After the blood pressure and heart rate became stable, $12.5 \mathrm{mg} / \mathrm{kg}$ of $\mathrm{L}$ NMMA acetate was injected from the femoral vein. L-MMMA acetate (Calbiochem Co., La Jolla, California) was dissolved in saline to make a solution of $12.5 \mathrm{mg} / \mathrm{ml}$, frozen and stored at $-20^{\circ} \mathrm{C}$ for no more than 6 weeks. Ten minutes after the injection of L-NMMA, the second measurement of both cardiac output and regional vascular resistances was performed similarly to the first one described above. The animal was sacrificed and the tissues were removed, weighed and placed in test tubes for counting. Brain, heart, left kidney, left and right testes and intestine (jejunum) were studied. Tissues were obtained as a whole organ except intestinc. Refcrence sample activity was also measured. The injection syringe and left ventricular cannula were counted for residual activity, and this count was subtracted from the initial count to determine total injected activity.

Data a nalysis and statistics: Reference sample flow rate was calculated from the flow rate of the blood collected. Cardiac output and regional vascular resistances were calculated as follows.

\section{Cardiac Output}

$=($ reference sample flow rate $\mathrm{x}$ injected activity $) /$ reference sample activity Regional Vascular Resistance

$=($ mean arterial pressure $\mathrm{x}$ reference sample activity $\mathrm{x}$ tissue weight $) /$ (reference sample flow rate $\mathrm{x}$ tissue activity).

Cardiac output was divided by body weight to calculate cardiac index $(\mathrm{m} l$ $\min ^{-1} 100 \mathrm{~g}$ body weight $\left.{ }^{-1}\right)$. Total peripheral resistance index $\left(\mathrm{mmHg} \mathrm{m} l^{-1} \mathrm{~min}\right.$ $100 \mathrm{~g}$ body weight) was calculated by dividing the mean arterial pressure by the cardiac index.

Values are given as mean \pm SEM. Data were analyzed by analysis of variance, followed by multiple comparisons made with Duncan's multiple range test. Student's t test was used where appropriate. Statistical significance was consid- 
ered to be $p<0.05$.

\section{Results}

Body weight was $372 \pm 9 \mathrm{~g}$ on the day of the experiment. Table I summarizes the hemodynamic parameter data. Injection of L-NMMA $12.5 \mathrm{mg} / \mathrm{kg}$ raised mean arterial pressure and decreased heart rate significantly $(p<0.05)$. Both the cardiac index and stroke volume index were decreased significantly $(p<0.05)$ by the injection of L-NMMA. Total peripheral resistance index was increased significantly $(p<0.05)$.

Table II represents the changes in regional vascular resistance of the tissues. Vascular resistance in brain, heart, left kidney and intestine increased significantly $(p<0.05)$ with L-NMMA. L-NMMA did not alter the resistances of the right or left testis significantly. The ratio of vascular resistance before and after the administration of L-NMMA differed significantly $(p<0.05)$ among the vascular beds ( $F$ value was 4.33 with one way analysis of variance). The ratio for the kidney was significantly $(p<0.05)$ higher than brain, heart, left testis and right testis. The ratio for the intestine was significantly $(p<0.05)$ higher than brain, left testis and right testis.

\section{Discussion}

We have shown that L-NMMA raises arterial pressure, decreases the cardiac index and elevates regional vascular resistances. Our study demonstrates that inhibition of NO synthesis in vivo results in large increases in blood pressure that can be attributed exclusively to increased total peripheral resistance, because the cardiac output and heart rate decreased invariably. These results are in agreement with other studies, ${ }^{10)}$ suggesting reciprocal changes in cardiac output and systemic vascular resistance in response to inhibition of $\mathrm{NO}$ synthesis by $\mathrm{L}$ -

Table I. Mean Arterial Pressure (MAP), Heart Rate (HR), Gardiac Index (CI), Stroke Volume Index (SVI) and Total Peripheral Resistance Index (TPRI) in Rats before (Control) and after Injection of $\mathrm{N}^{\mathrm{G}}$-Monomethyl-L-Arginine (L-NMMA)

\begin{tabular}{lcc}
\hline & Control & L-NMMA \\
\hline MAP $(\mathrm{mmHg})$ & $119 \pm 4$ & $139 \pm 7^{*}$ \\
$\mathrm{HR}\left(\right.$ beats $\left.\mathrm{min}^{-1}\right)$ & $408 \pm 8$ & $395 \pm 11^{*}$ \\
$\mathrm{CI}\left(\mathrm{m} l \mathrm{~min}^{-1} 100 \mathrm{~g} \mathrm{BW}{ }^{-1}\right)$ & $29.2 \pm 1.8$ & $19.7 \pm 2.4^{*}$ \\
$\mathrm{SVI}\left(\mathrm{m} l \mathrm{~min}^{-1} \mathrm{beats}^{-1} 100 \mathrm{~g} \mathrm{BW}^{-1}\right)$ & $72 \pm 5$ & $51 \pm 7^{*}$ \\
TPRI $\left(\mathrm{mmHg} \mathrm{m}^{-1} \operatorname{min~} 100 \mathrm{~g} \mathrm{BW}\right)$ & $4.2 \pm 0.3$ & $8.0 \pm 1.3^{*}$ \\
\hline
\end{tabular}

Values are mean $\pm \mathrm{SEM}$. BW=body weight; ${ }^{*} p<0.05$ vs. Control. 
Table II. Regional Vascular Resistance ( $\mathrm{mmHg}{ }^{-1} \mathrm{~min}$ g) in Brain, Heart, Left

Kidney, Intestine, Left Testis and Right Testis Before (Control) and After Injection of $N^{\mathrm{C}}$-Monomethyl-L-Arginine (L-NMMA)

\begin{tabular}{lccc}
\hline & $\begin{array}{c}\text { Control } \\
\left(\mathrm{mmHg} \mathrm{m} l^{-1} \mathrm{~min} \mathrm{~g}\right)\end{array}$ & $\begin{array}{c}\text { L-NMMA } \\
\left(\mathrm{mmHg} \mathrm{m} l^{-1} \mathrm{~min} g\right)\end{array}$ & L-NMMA/Control \\
\hline Brain & $268 \pm 35$ & $349 \pm 69^{*}$ & $1.26 \pm 0.09$ \\
Heart & $44 \pm 6$ & $64 \pm 15^{*}$ & $1.54 \pm 0.23$ \\
Left kidney & $31 \pm 4$ & $66 \pm 7^{*}$ & $2.30 \pm 0.35^{+}$ \\
Intestine & $131 \pm 32$ & $240 \pm 53^{*}$ & $1.98 \pm 0.21^{*}$ \\
Left testis & $1027 \pm 143$ & $1117 \pm 179$ & $1.08 \pm 0.05$ \\
Right testis & $1078 \pm 179$ & $1220 \pm 172$ & $1.26 \pm 0.19$ \\
\hline
\end{tabular}

Values are mean \pm SEM. L-NMMA/Control=Ratio of regional vascular resistance before and after the injection of L-NMMA. ${ }^{*} p<0.05$ vs. Control, ${ }^{+} p<0.05$ vs. brain, heart, left testis and right testis, ${ }^{\sharp} p<0.05$ vs. brain, left testis and right testis.

arginine analogues. Furthermore, the increase in systemic vascular resistance was due to increased regional resistance in the majority of organs studied. These data provide evidence that NO mediates regional circulatory control in a variety of regional vascular beds.

The present observations suggest that the resistance of vascular beds may be regulated by endogenous NO synthesis. However, the extent of regulation may differ among the various vascular beds because the vascular resistance in the testes did not increase with L-NMMA and the increment of renal vascular resistance with L-NMMA was greater than other tissues. These results are in good agreement with a recent report ${ }^{10}$ of marked regional heterogeneity in the magnitude of NO-mediated vascular tone. The mechanisms that control the activation of the NO synthetic pathway in vivo remain to be established, but could involve mechanical stimulation of endothelial cells due to shear stress resulting from pulsatile flow or other physical factors. The difference in physical forces on endothelium in individual tissues may be an explanation for the difference in the response to $\mathrm{NO}$ synthesis inhibition. This would be consistent with observations in intact vascular networks in vitro. ${ }^{11)}$ In the present experiment, however, rats were uninephrectomized 4 weeks before the acute experiments. Thus, the left kidney would be hypertrophied and receive a high renal blood flow, which may make a difference in physical forces on the renal vasculature from other vascular beds. Uninephrectomy is performed frequently to induce animal models of hypertension, and it is valuable to study the hemodynamic status of these animals. Since we did not have a chance to study the effect of L-NMMA on regional vascular resistance in unnephrectomized control rats, a difference in the response between an intact kidney and a hypertrophied kidney due to contralateral nephrectomy cannot be excluded. It is also necessary to study the responses of other various vascular beds to the different doses of L-NMMA to make these points clear. 
In conclusion, intravenous injection of L-NMMA raised mean arterial pressure and some regional vascular resistances in rats. The results indicate that the resistance of vascular beds is regulated by NO synthesis. The magnitude of regulation may differ among the various vascular beds.

\section{ACKNOWLEDGMENTS}

We thank Clark Efaw for his excellent technical help.

\section{REFERENCES}

1. Furchgott RF, Zawadzki JV: The obligatory role of endothelial cells in the relaxation of arterial smooth muscle by acetylcholine. Nature 288: 373, 1980

2. Palmer RMJ, Ferrige AG, Moncada S: Nitric oxide release accounts for the biological activity of endothelium-derived relaxing factor. Nature 327: 524, 1987

3. Palmer RMJ, Ashton DS, Moncada S: Vascular endothelial cells synthesize nitric oxide from Larginine. Nature 333: 664, 1988

4. Schmidt HHHW, Nau H, Wittoht W, Gerlach J, Prescher K-E, Klein MM, Niroomand F, Böhme E: Arginine is a physiological precursor of endothelium-derived nitric oxide. Eur J Pharmacol 154: 213, 1988

5. Palmer RMJ, Rees DD, Ashton DS, Moncada S: L-arginine is the physiological precursor for the formation of nitric oxide in endothelium-dependent relaxation. Biochem Biophys Res Commun 153: 1251,1988

6. Sakuma 1, Stuehr DJ, Gross SS, Nathan G, Levi R: Identification of arginine as a precursor of endothelium-derived relaxing factor. Proc Natl Acad Sci USA 85: 8664, 1988

7. Rees DD, Palmer RMJ, Moncada S: Role of endothelium-derived nitric oxide in the regulation of blood pressure. Proc Natl Acad Sci USA 86: 3375, 1989

8. Aisaka $\mathrm{K}$, Gross SS, Griffith $\mathrm{OW}$, Levi R: $\mathrm{N}^{\mathrm{G}}$-methylarginine, an inhibitor of endothelium-derived nitric oxide synthesis, is a potent pressor agent in the guinea pig; does nitric oxide regulate blood pressure in vivo? Biochem Biophys Res Commun 160: 881, 1989

9. Gardiner SM, Compton AM, Bennett T, Palmer RMJ, Moncada S: Control of regional blood flow by endothelium-derived nitric oxide. Hypertension 15: 486, 1990

10. Greenblatt EP, Loeb AL, Longnecker DE: Marked regional heterogeneity in the magnitude of EDRF/NO-mediated vascular tone in awake rats. J Cardiovasc Pharmcol 21: 235, 1993

11. Griffith TM, Edwards DH, Davies RL, Harrison TJ, Evans KT: EDRF coordinates the behaviour of vascular resistance vessels. Nature 329: 442, 1987 